\title{
Comparative study of risk factors in patients undergoing coronary or femoropopliteal artery bypass grafting
}

\author{
F Mainard, J L Auget, P Vest, Y Madec
}

\begin{abstract}
Objective-To compare risk factors in two populations of patients with advanced atheroma requiring coronary or femoropopliteal artery bypass grafting to try to account for the different localisations of vascular disease.
\end{abstract}

Design-Cross sectional epidemiological study.

Setting-Cardiovascular surgery department of a university hospital.

Subjects-464 men (mean age 59.25 (SD 8.57) years) undergoing coronary artery bypass grafting; 74 men (mean age $56 \cdot 28$ (13.3) years) undergoing femoropopliteal artery bypass grafting; and 204 control men (mean age 45.07 (6.59) years) who had been recruited in a preventive medicine department.

Interventions-Blood samples were drawn 24 hours before surgery.

Methods-Lipid and lipoprotein concentrations were measured for each patient and with adjustment for age were compared by analysis of covariance. The main risk factors (smoking, arterial hypertension, obesity, and diabetes) were determined by a standardised history, and the $\chi^{2}$ test was used to compare the results in the two patient groups. Pairwise comparisons between the three populations were performed by logistic discriminant analysis.

Results-Both patient groups showed a significant rise in triglyceride concentration and in the ratio of total cholesterol to high density lipoprotein cholesterol (R1) and a drop in apolipoprotein $A I$ and high density lipoprotein cholesterol concentrations. Disturbances were greater in patients undergoing coronary artery bypass grafting than in those undergoing femoropopliteal artery bypass grafting for the $R 1$ ratio, apolipoprotein $B$ concentration, and the ratio of apolipoprotein AI to apolipoprotein B (R2). A higher proportion of smokers was found in the femoropopliteal bypass group than in the coronary bypass group, whereas patients in the coronary bypass group were often obese. Logistic discriminant analysis with adjustment for age and with the coronary bypass as the reference group selected three factors: smoking, the $R 2$ ratio, and obesity.

Conclusion-Disturbances in lipid and apoprotein concentrations varied with respect to bypass site. Other risk factors played a part in accelerating the atherogenic process, especially smoking in patients undergoing femoropopliteal artery bypass grafting and, to a lesser degree, obesity in patients undergoing coronary artery bypass grafting.

(Br Heart f 1994;72:542-547)

Various epidemiological studies have shown the role of lipids and lipoproteins in atherogenesis. These substances accumulate preferentially in cerebral vessels, where they may cause cerebrovascular accidents; in coronary arteries, where they may be responsible for clinical manifestations of angina and ultimately lead to myocardial infarction; or in arteries of the lower limbs, where they can produce arteritis. Although risk factors for these three categories of cardiovascular disease have been previously investigated ${ }^{1}$ and comparisons performed with control populations, few studies have addressed the relation of risk factors to the site of atheroma. We compared risk factors in two populations with advanced atheroma requiring coronary or femoropopliteal artery bypass grafting to try to account for the different localisations of vascular disease.

Patients and methods

POPULATIONS

The procedures followed were in accordance with the Helsinki declaration, and all subjects gave their informed consent.

The patients studied had been admitted to the cardiovascular surgery department of the $G$ and $R$ Laennëc Hospital (Nantes University Hospital) for coronary or femoropopliteal artery bypass grafting. They were recruited between 1986 and 1989 (when few patients were treated with hypolipidaemic drugs before surgery). Women were not included because of hormonal variations in the age range of the patients studied. The coronary bypass group was composed of 464 men (mean age (SD): 59.25 (8.57) years; range 33-81) and the femoropopliteal bypass group of 74 men (56.28 (13.03) years; range 32-93).

These patients were not representative of the total population with coronary artery disease or arteritis of the legs but corresponded to groups with an advanced state of atheroma, implying a need for surgery. \\ 21 April 1994
}


The two types of bypass surgery were not performed in emergency conditions but were scheduled after coronary arteriography indicated lesions (number, site, and size) in patients undergoing coronary artery bypass grafting or after ultrasonography, Doppler examination, and arteriography of the lower limbs in patients undergoing femoropopliteal artery bypass grafting.

Lipids and lipoprotein concentrations were analysed for each patient, and the presence of the other main risk factors (smoking, arterial hypertension, obesity, and diabetes) was determined from a standardised history. These factors were strictly defined as follows. Patients who smoked within the past two years were considered to be smokers. Hypertensive patients had a systolic blood pressure above $160 \mathrm{~mm} \mathrm{Hg}$ and a diastolic blood pressure above $95 \mathrm{~mm} \mathrm{Hg}$ or had been treated for arterial hypertension. Diabetic patients had been treated for insulin dependent or non-insulin dependent diabetes. Obese patients were $20 \%$ over their theoretical weight as calculated by the Lorentz formula: theoretical weight = $T-100-(T-150 / a)$ where $T$ is height in $\mathrm{cm}$ and $a$ is 4 (for a man).

Patients undergoing coronary artery bypass grafting who had been treated with hypolipidaemic drugs and $\beta$ blockers were excluded from the study.

The control group, recruited among hospital and university staff by the preventive medicine department, was composed of 204 men (mean age 45.07 (6.59) years; range 35-63). Subjects had no cardiovascular history (angina pectoris, myocardial infarction), cerebrovascular history, or arteritis of the lower limbs. They were euthyroid, did not take any drugs affecting the lipid profile, and were not hypertensive, obese, diabetic, or smokers. The last criterion may seem arbitrary and unrealistic in that some authors have excluded diabetics and hypertensive subjects from their control groups but have included smokers. ${ }^{2-4}$ Such a choice seemed illogical to us: all the main risk factors (smoking, hypertension, diabetes, and obesity) should either be totally excluded or be totally retained. If all the main risk factors were totally retained the control population would be a group without cardiovascular history. For ethical reasons angiography and arteriography of the lower limbs were not performed in control subjects.

MEASUREMENT OF LIPID, LIPOPROTEIN, AND APOPROTEIN CONCENTRATIONS

Blood samples were drawn 24 hours before surgery to avoid any disturbances of lipoprotein balance due to extracorporeal circulation during surgery or stress caused by the operation. ${ }^{5}$ The patient had fasted for 12 hours and had taken no preoperative drugs.

Blood from venous puncture in the crook of the arm was collected in $5 \mathrm{ml}$ tubes containing $100 \mu \mathrm{l}$ ethylenediaminetetra-acetic acid (EDTA) $19 \mathrm{mmol} / \mathrm{l}$ and centrifuged at $1500 \mathrm{~g}$ for 10 minutes at $15^{\circ} \mathrm{C}$. Lipid variables were determined by assays on the same day in plasma stored at $4^{\circ} \mathrm{C}$. Cholesterol and tri- glyceride assays were performed by enzymatic methods based on the Trinder reaction ${ }^{6}$ using, respectively, a peroxidase antiperoxidase enzymatic cholesterol kit (reference 230691) and a peroxidase antiperoxidase enzymatic triglyceride kit (reference 759350, Boehringer, Meylan, France). Standard serum (calibrated for automated systems, reference 759350) and control serum (Precilip EL, reference 225053, both supplied by Boehringer) and the biochemical automatic analyser (Hitachi 704) were the same for both assays.

High density lipoprotein cholesterol was isolated by a phosphotungstate-magnesium chloride method. ${ }^{7}$ High density lipoprotein cholesterol was assayed in the supernatant by the method used for total cholesterol.

Apolipoprotein AI and apolipoprotein B were evaluated by an immunonephelometric method according to the protocol of Munscher et al. ${ }^{8}$ Antibodies, standards, and controls were supplied by Behring (Rueil Malmaison, France). From total cholesterol and high density lipoprotein cholesterol values, on the one hand, and apolipoprotein AI and apolipoprotein $B$ values, on the other, we determined ratios referred to respectively as $R 1$ and R2, which change inversely and express atherogenic risk more accurately.

It would have been possible to determine low density lipoprotein cholesterol according to the formula of Friedewald et al based on three values (total cholesterol, high density lipoprotein cholesterol, and triglycerides). ${ }^{9}$ The drawback with this method is the cumulative percentages of error resulting from the three assays. Moreover, calculation is limited by a threshold concentration for triglyceride, thus excluding expression of results for some hypertriglyceridaemic serum samples. For these reasons, only apolipoprotein B was used to determine low density lipoprotein cholesterol.

\section{STATISTICAL METHODS}

Statistical analysis was performed using the SYSTAT package. ${ }^{10}$ As a preliminary study had indicated that age was highly correlated with most lipid variables, comparisons of means with adjustment for age were performed by analysis of covariance. The $\chi^{2}$ test was used to compare the percentages of patients in the two groups who had risk factors other than lipid concentrations. A significance level of 0.005 was chosen for Bonferroni's procedure. ${ }^{11}$

Table 1 Distribution of risk factors for atheroma in two patient populations. Values are numbers (percentages) of patients

\begin{tabular}{llll}
\hline & $\begin{array}{l}\text { Coronary } \\
\text { bypass } \\
(n=464)\end{array}$ & $\begin{array}{l}\text { Femoropopliteal } \\
\text { bypass } \\
(n=74)\end{array}$ & Pvalue* \\
\hline Smoking & $247(53)$ & $62(84)$ & $<0.001$ \\
Arterial hypertension & $161(35)$ & $16(22)$ & 0.022 \\
Obesity & $183(39)$ & $16(22)$ & 0.003 \\
Diabetes & $67(14)$ & $11(15)$ & 0.92 \\
\hline
\end{tabular}

${ }^{\star} \chi^{2}$ test; $\mathrm{P}<0.05$ is significant; Bonferroni's procedure $a=0.005$. 
Table 2 Comparison of mean (SD) lipid values in the two patient populations (excluding diabetic subjects) and controls

\begin{tabular}{|c|c|c|c|c|c|}
\hline & \multirow[b]{2}{*}{$\begin{array}{l}\text { Coronary bypass } \\
(n=397)\end{array}$} & \multirow[b]{2}{*}{$\begin{array}{l}\text { Femoropopliteal } \\
\text { bypass } \\
(n=204)\end{array}$} & \multirow[b]{2}{*}{$\begin{array}{l}\text { Controls } \\
(n=204)\end{array}$} & \multicolumn{2}{|l|}{ Pvalue* } \\
\hline & & & & $\begin{array}{l}\text { Coronary } \\
\text { bypass } \\
v \text { controls }\end{array}$ & $\begin{array}{l}\text { Femoropopliteal } \\
\text { bypass } \\
v \text { controls }\end{array}$ \\
\hline $\begin{array}{l}\text { Total cholesterol }(\mathrm{mmol} / \mathrm{l}) \\
\text { Triglycerides }(\mathrm{mmol} / \mathrm{l}) \\
\text { HDL cholesterol }(\mathrm{mmol} / \mathrm{l}) \\
\text { R1 (total cholesterol: HDL cholesterol) } \\
\text { Apolipoprotein AI }(\mathrm{g} / \mathrm{l}) \\
\text { Apolipoprotein B (g/1) } \\
\text { R2 (apolipoprotein AI: apolipoprotein B) }\end{array}$ & $\begin{array}{l}6.07(1 \cdot 14) \\
1.56(0.96) \\
1.14(0.29) \\
5 \cdot 60(1.61) \\
1.19(0.25) \\
1.33(0.31) \\
0.93(0.28)\end{array}$ & $\begin{array}{l}5.72(1.04) \\
1.90(0.90) \\
1.21(0.34) \\
5.06(1.52) \\
1.26(0.28) \\
1.23(0.29) \\
1.08(0.37)\end{array}$ & $\begin{array}{l}5.90(0.79) \\
1.26(0.41) \\
1.51(0.33) \\
4 \cdot 10(1.07) \\
1.45(0.24) \\
1.22(0.22) \\
1.24(0.33)\end{array}$ & $\begin{array}{l}<0.003 \\
<0.001 \\
<0.001 \\
<0.001 \\
<0.001 \\
<0.001 \\
<0.001\end{array}$ & $\begin{array}{c}0.10 \\
<0.001 \\
<0.001 \\
<0.001 \\
<0.001 \\
0.59 \\
0.011\end{array}$ \\
\hline
\end{tabular}

HDL, high density lipoprotein.

*Bonferroni procedure $a=0.005$.

Table 3 Comparison of mean (SD) lipid values in the two patient populations (including diabetic patients)

\begin{tabular}{|c|c|c|c|}
\hline & $\begin{array}{l}\text { Coronary bypass } \\
(n=464)\end{array}$ & $\begin{array}{l}\text { Femoropopliteal bypass } \\
(n=74)\end{array}$ & $P$ value \\
\hline $\begin{array}{l}\text { Total cholesterol }(\mathrm{mmol} / \mathrm{l}) \\
\text { Triglycerides }(\mathrm{mmol} / \mathrm{l}) \\
\text { HDL cholesterol }(\mathrm{mmol} / \mathrm{l}) \\
\text { R1 (total cholesterol: } \mathrm{HDL} \text { cholesterol) } \\
\text { Apolipoprotein AI }(\mathrm{g} / \mathrm{l}) \\
\text { Apolipoprotein B (g/1) } \\
\text { R2 (apolipoprotein AI: apolipoprotein B) }\end{array}$ & $\begin{array}{l}6.04(1.12) \\
1.98(1.03) \\
1.13(0.30) \\
5.64(1.75) \\
1.18(0.25) \\
1.32(0.30) \\
0.94(0.29)\end{array}$ & $\begin{array}{l}5.70(1.05) \\
1.99(1.00) \\
1.20(0.34) \\
5.07(1.53) \\
1.24(0.28) \\
1.22(0.29) \\
1.07(0.37)\end{array}$ & $\begin{array}{l}0.006 \\
0.72 \\
0.05 \\
0.002 \\
0.03 \\
0.004 \\
<0.001\end{array}$ \\
\hline
\end{tabular}

Logistic discriminant analysis with adjustment for age was performed in the pairwise comparison of the three groups through simultaneous treatment of quantitative (lipid) and qualitative binary (other risk factors) variables. A stepwise procedure was used to select the most discriminant variables and their interaction.

\section{Results}

RISK FACTORS OTHER THAN LIPID VALUES IN THE TWO PATIENT GROUPS

Table 1 shows the distribution of risk factors in each patient group. The $\chi^{2}$ test specified the degree of significance expressed as the difference in the distribution of each risk factor between the two groups. There were more smokers $(P<0.001)$ in the femoropopliteal bypass group. In this respect, calculation of the odds ratio showed that for a smoker with a vascular problem the risk of femoral atheroma was 4.54 times greater than the risk of coronary atheroma.

LIPID AND APOLIPOPROTEIN VARIABLES IN THE THREE GROUPS

Table 2 shows the comparisons of means with adjustment for age for the two patient populations (excluding diabetic subjects) versus controls.

Compared with the controls patients undergoing coronary artery bypass grafting showed significantly increased values for total cholesterol, triglyceride, and apolipoprotein $B$, and the $R 1$ ratio and significantly decreased values for high density lipoprotein cholesterol, apolipoprotein $\mathrm{AI}$, and the R2 ratio.

Our observations for patients undergoing femoropopliteal artery bypass grafting were the same except that total cholesterol and apolipoprotein B values were not significantly different from those of controls.

The comparative study of mean values in the two groups of patients (including diabetic subjects) (table 3) showed significantly lower values for the $R 1$ ratio and apolipoprotein $B$ and a higher $\mathrm{R} 2$ ratio (total cholesterol concentration being significantly lower but borderline).

INFLUENCE OF OTHER RISK FACTORS ON LIPID AND APOLIPOPROTEIN VALUES

Table 4 shows lipoprotein and apolipoprotein values for smokers and non-smokers in the two patient groups. Analysis of covariance accounting for age showed a significant increase in triglyceride concentrations in smokers undergoing coronary artery bypass grafting and a significant decrease in high density lipoprotein cholesterol concentration in smokers undergoing femoropopliteal artery bypass grafting (a borderline significant rise being observed for the $R 1$ ratio in the femoropopliteal bypass group).

In table 5 analysis of covariance showed a significant increase in triglyceride concentration in obese patients undergoing coronary

Table 4 Influence of smoking on mean (SD) lipid values in the two patient populations

\begin{tabular}{|c|c|c|c|c|c|c|}
\hline & \multicolumn{2}{|c|}{ Coronary bypass $(n=462)$} & \multirow[b]{2}{*}{ Pvalue* } & \multicolumn{2}{|c|}{ Femoropopliteal bypass $(n=74)$} & \multirow[b]{2}{*}{ Pvalue } \\
\hline & $\begin{array}{l}\text { Smokers } \\
(n=247)\end{array}$ & $\begin{array}{l}\text { Non-smokers } \\
(n=217)\end{array}$ & & $\begin{array}{l}\text { Smokers } \\
(n=62)\end{array}$ & $\begin{array}{l}\text { Non-smokers } \\
(n=12)\end{array}$ & \\
\hline $\begin{array}{l}\text { Total cholesterol }(\mathrm{mmol} / \mathrm{l}) \\
\text { Triglycerides }(\mathrm{mmol} / \mathrm{l}) \\
\text { HDL cholesterol }(\mathrm{mmol} / \mathrm{l}) \\
\text { R1 (total cholesterol: HDL cholesterol) } \\
\text { Apolipoprotein AI (g/1) } \\
\text { Apolipoprotein B (g/1) } \\
\text { R2 (apolipoprotein AI: apolipoprotein B) }\end{array}$ & $\begin{array}{l}6 \cdot 08(1 \cdot 10) \\
2 \cdot 16(1 \cdot 16) \\
1.12(0 \cdot 29) \\
5.75(1 \cdot 78) \\
1.27(0 \cdot 25) \\
1.33(0 \cdot 30) \\
0.92(0.30)\end{array}$ & $\begin{array}{l}6.00(1.14) \\
1.78(0.83) \\
1.14(0.32) \\
5.52(1.70) \\
1.20(0.24) \\
1.30(0.30) \\
0.97(0.27)\end{array}$ & $\begin{array}{l}0 \cdot 83 \\
0 \cdot 002 \\
0 \cdot 97 \\
0 \cdot 81 \\
0 \cdot 37 \\
0 \cdot 95 \\
0 \cdot 55\end{array}$ & $\begin{array}{l}5 \cdot 72(1 \cdot 10) \\
2 \cdot 10(1 \cdot 04) \\
1 \cdot 15(0 \cdot 32) \\
5 \cdot 28(1 \cdot 52) \\
1 \cdot 22(0 \cdot 26) \\
1 \cdot 23(0 \cdot 30) \\
1 \cdot 05(0 \cdot 38)\end{array}$ & $\begin{array}{l}5.59(0.84) \\
1.43(0.49) \\
1.46(0.35) \\
3.99(1.03) \\
1.38(0.35) \\
1.14(0.23) \\
1.21(0.29)\end{array}$ & $\begin{array}{l}0.63 \\
0.06 \\
0.003 \\
0.008 \\
0.09 \\
0 \cdot 18 \\
0 \cdot 11\end{array}$ \\
\hline
\end{tabular}


Table 5 Influence of obesity on mean (SD) lipid values in the two patient populations

\begin{tabular}{|c|c|c|c|c|c|c|}
\hline & \multicolumn{2}{|c|}{ Coronary bypass ( $n=464)$} & \multirow[b]{2}{*}{$P$ value* } & \multicolumn{2}{|c|}{ Femoropopliteal bypass ( $n=74$} & \multirow[b]{2}{*}{$P$ value } \\
\hline & $\begin{array}{l}\text { Obese } \\
(n=183)\end{array}$ & $\begin{array}{l}\text { Non-obese } \\
(n=281)\end{array}$ & & $\begin{array}{l}\text { Obese } \\
(n=16)\end{array}$ & $\begin{array}{l}\text { Non-obese } \\
(n=558)\end{array}$ & \\
\hline Total cholesterol $(\mathrm{mmol} / \mathrm{l})$ & $6 \cdot 09(1 \cdot 10)$ & $6 \cdot 00(1 \cdot 13)$ & 0.56 & $6 \cdot 17(1 \cdot 28)$ & $5.57(0.95)$ & 0.04 \\
\hline Triglycerides $(\mathrm{mmol} / \mathrm{l})$ & $2 \cdot 21(1 \cdot 20)$ & $1.84(0.89)$ & $<0.001$ & $2.44(1.53)$ & $1.86(0.77)$ & 0.04 \\
\hline HDL cholesterol $(\mathrm{mmol} / \mathrm{l})$ & $1 \cdot 10(0 \cdot 28)$ & $1 \cdot 16(0.31)$ & 0.06 & $1.25(0.33)$ & $1.18(0.35)$ & $0 \cdot 48$ \\
\hline R1 (total cholesterol: HDL cholesterol) & $5 \cdot 87(1.71)$ & $5.49(1.76)$ & 0.04 & $5.29(2.04)$ & $5.01(1.37)$ & 0.51 \\
\hline Apolipoprotein AI $(\mathrm{g} / \mathrm{l})$ & $1 \cdot 16(0 \cdot 25)$ & $1.20(0 \cdot 24)$ & $0 \cdot 10$ & $1.31(0.33)$ & $1.23(0.26)$ & 0.27 \\
\hline Apolipoprotein B (g/l) & $1.34(0.30)$ & $1 \cdot 30(0.30)$ & $0 \cdot 22$ & $1.28(0.40)$ & $1.20(0.25)$ & $0 \cdot 39$ \\
\hline R2 (apolipoprotein AI: apolipoprotein B) & $0.89(0 \cdot 27)$ & $0.97(0.29)$ & 0.01 & $1 \cdot 11(0.45)$ & $1.06(0.35)$ & 0.63 \\
\hline
\end{tabular}

HDL, high density lipoprotein.

$\star$ Bonferroni procedure $a=0.005$.

bypass but not in those undergoing femoropopliteal bypass. The lack of significance may have been due to the lower number of patients in the latter group.

\section{LOGISTIC DISCRIMINANT ANALYSIS}

In comparisons with controls, age adjusted logistic discriminant analysis (table 6) selected triglyceride and apolipoprotein $\mathrm{AI}$ values, the $R 1$ ratio, and the interaction between age and R1 for patients undergoing coronary artery bypass grafting (excluding diabetic subjects). Coefficients in the logistic model were positive for triglyceride values and the $\mathrm{R} 1$ ratio and negative for apolipoprotein concentration, suggesting that triglyceride concentration and R1 but not apolipoprotein AI concentration were conducive to cardiovascular disease in these patients.

Table 6 Results of logistic discriminant analysis between patients undergoing coronary artery bypass grafting (excluding diabetic patients) and controls

\begin{tabular}{lclrrr}
\hline Variable & Estimated coefficient & $S E$ & T ratio & P value & Odds ratio \\
\hline Constant & -19.94 & 4.43 & -4.50 & $<0.001$ & \\
Age & 0.43 & 0.09 & 5.01 & $<0.001$ & 1.54 \\
Triglyceride value & 1.29 & 0.32 & 4.03 & $<0.001$ & 3.62 \\
Apolipoprotein AI value & -3.68 & 0.74 & -4.97 & $<0.001$ & 0.03 \\
R1 ratio & 2.38 & 0.80 & 2.97 & 0.003 & 10.80 \\
Age $\times$ R1 & -0.04 & 0.02 & -2.63 & 0.009 & 0.96 \\
\hline
\end{tabular}

Likelihood ratio statistic $\mathrm{G}=459 \cdot 3, \mathrm{df}=1, \mathrm{P}<0.001$.

Table 7 Results of logistic discriminant analysis between patients undergoing femoral artery bypass grafting (excluding diabetic patients) and controls

\begin{tabular}{lclrrc}
\hline Variable & Estimated coefficient & $S E$ & Tratio & P value & Odds ratio \\
\hline Constant & -19.58 & 4.58 & -4.28 & $<0.001$ & \\
Age & 0.30 & 0.09 & 3.42 & 0.001 & 1.35 \\
Triglyceride value & 1.36 & 0.40 & 3.37 & 0.001 & 3.89 \\
R1 ratio & 1.92 & 0.86 & 2.22 & 0.026 & 6.81 \\
Age $\times$ R1 & -0.03 & 0.02 & -1.91 & 0.057 & 0.97 \\
\hline
\end{tabular}

Likelihood ratio statistic $\mathrm{G}=459 \cdot 3, \mathrm{df}=1, \mathrm{P}<0 \cdot 001$.

Table 8 Results of logistic discriminant analysis of the two patient populations (including diabetic patients)*

\begin{tabular}{lllrrr}
\hline Variable & Estimated coefficient & $S E$ & Tratio & Pvalue & Odds ratio \\
\hline Constant & -2.74 & 0.97 & -2.83 & 0.005 & \\
Age & -0.02 & 0.01 & -1.45 & 0.15 & 0.98 \\
Triglyceride value & 1.47 & 0.34 & 4.28 & $<0.001$ & 4.33 \\
R1 ratio & 1.31 & 0.40 & 3.31 & $<0.001$ & 3.71 \\
Age $\times$ R1 & -0.82 & 0.31 & -2.66 & 0.008 & 0.44
\end{tabular}

Likelihood ratio statistic $\mathrm{G}=459.3, \mathrm{df}=1, \mathrm{P}<0.001$

$\star$ Patients undergoing coronary artery bypass grafting were reference group.
Selection of the interaction between age and R1 in this analytic model showed that the variation in the $R 1$ ratio with age was not the same in patient and control populations. An increase of 1 in the $R 1$ ratio for a subject meant that cardiovascular risk was 10.79 times greater.

The same analytical procedure for patients (excluding diabetic subjects) undergoing femoropopliteal artery bypass grafting and controls selected triglyceride concentration, $\mathrm{R} 1$, and the interaction between age and $\mathrm{R} 1$ (table 7). Coefficients for triglyceride concentration and R1 were positive, as for the other patient group versus controls.

Table 8 shows the results of discriminant analysis when the two patient groups were compared (the reference group being the coronary bypass group) and diabetic subjects were included. The selected factors were smoking, R2, and obesity. The coefficients in the logistic model were positive for smoking and the $\mathrm{R} 2$ ratio and negative for obesity. The odds were 4.33 times greater that a smoker with atheroma would belong to the femoropopliteal bypass group rather than the coronary bypass group.

\section{Discussion}

Univariate analysis accounting for age showed that lipid and lipoprotein variables in patients undergoing coronary artery bypass grafting were significantly disturbed compared with those in controls. These results are in agreement with many previous studies of men with coronary disease, notably recent studies by Genest et al and Sigurdsson et al. ${ }^{12}{ }^{13}$ Similar disturbances, except for total cholesterol, apolipoprotein $B$ and the $R 2$ ratio, were also noted in patients undergoing femoropopliteal artery bypass grafting. These results are consistent with those of Pomrehn et al and Senti et $a .^{2}{ }^{14}$

The discriminant factors for patients undergoing coronary artery bypass grafting were triglyceride and apolipoprotein $\mathrm{AI}$ values and the ratio of total cholesterol to high density lipoprotein cholesterol (R1). Various epidemiological studies have reported that high density lipoprotein cholesterol is a major risk factor in subjects with coronary artery disease, whether considered separately ${ }^{315-18}$ or in association with total cholesterol. Our results are in agreement with our previous data ${ }^{19}$ and 
with those of Castelli and Lehtonen et al, who emphasised the importance of the $\mathrm{R} 1$ ratio as well as apolipoprotein AI. ${ }^{2021}$ Triglycerides are also an important risk factor, and their role in coronary artery disease has been shown. ${ }^{22} 24$

Triglycerides and the $R 1$ ratio were also found to be discriminant factors in patients undergoing femoropopliteal artery bypass grafting. These results are consistent with those of Trayner et al for the R1 ratio ${ }^{25}$ and those of Senti et al for triglycerides. ${ }^{2}$ Senti et al considered that triglycerides of intermediary density and very low density lipoproteins are particularly important because of the catabolic disorders of these lipoproteins and their remnants.

Patients undergoing coronary artery bypass grafting tended to have more disturbed lipid and lipoprotein values, suggesting that other risk factors may have a greater influence on the atherosclerotic process in many subjects with peripheral vascular disease. In fact, our study showed that more of the femoropopliteal bypass group than the coronary bypass group smoked.

Age adjusted analysis in patients undergoing femoropopliteal artery bypass grafting showed that smokers had a significant decrease in high density lipoprotein cholesterol and a significant increase in the $\mathrm{R} 1$ ratio. Conversely, the same analysis in the other patients showed that high density lipoprotein cholesterol values were not significantly higher in smokers, unlike findings in other studies. ${ }^{26-28}$ This suggests that lipid and lipoprotein variables in subjects with arteritis of the lower limbs are more sensitive to the effects of smoking.

Obesity also influenced triglyceride concentration in patients undergoing coronary artery bypass grafting. The association of hypertriglyceridemia with obesity has been reported previously. ${ }^{29-31}$

Analysis of all these risk factors in the two bypass groups indicated three selective factors: smoking, the $\mathrm{R} 2$ ratio, and obesity. Kannel and Shurtleff have also emphasised that smoking in subjects with predisposing factors can accelerate the atherogenic process and lead to intermittent claudication. ${ }^{32}$ Smoking not only affects lipid and lipoprotein variables but also haemorrheologic factors (decreased erythrocyte deformability and increased blood viscosity, which can result in poor oxygenation of tissues). Moreover, smokers have a much higher blood carboxyhaemoglobin concentration than non-smokers, thus reducing the capacity of haemoglobin to carry oxygen. ${ }^{33}$

The $R 1$ ratio is a significant factor in discriminating between either group of atheromatous patients and controls; the $R 2$ ratio is an important discriminant factor between the two groups of patients. This role of the ratio, which to our knowledge has not been considered in previous studies, indicates the usefulness of determining apolipoprotein $\mathrm{AI}$ and apolipoprotein B values in such patients.

Obesity, the third factor selected, was more apparent in patients undergoing coronary artery bypass grafting, causing disorders in the metabolism of very low density lipoproteins and high density lipoprotein. ${ }^{31}$ However, this mechanism does not explain why the process has a preferential effect on coronary arteries.

Our study indicates that both bypass groups had disturbed lipid and lipoprotein variables. However, the abnormalities were greater in the coronary bypass group than in the femoropopliteal bypass group, particularly for the $\mathrm{R} 2$ ratio. Other risk factors thus played a part in accelerating the atherogenic process, especially smoking in patients undergoing femoropopliteal artery bypass grafting and, to a lesser degree, obesity in patients undergoing coronary artery bypass grafting. The incidence of smoking and obesity on lipid and lipoprotein variables implies that these factors should be eliminated before any drug treatment is started.

We thank Professor JL Michaud (cardiovascular surgery department, $G$ and R Laënnec Hospital, Nantes University department, G and R Laënnec Hospital, Nantes University and Yvelyne Daniel for secretarial help.

1 Gordon T, Kannel WB. Predisposition to atherosclerosis in the head, heart and legs. The Framingham Study. in the head, heart and

2 Senti $M$, Nogues X, Pedro-Botet J, Vidal-Barraquer F. Lipoprotein profile in men with peripheral vascular disease: role of intermediate density lipoproteins and apolipoprotein E phenotypes. Circulation 1992;85:30-6.

3 Pauciullo P, Rubbo P, Marotta G, Carbone C, Cortese C, Caruso MG, et al. Abnormalities in serum lipoprotein composition in patients with premature coronary heart disease compared to serum lipid matched controls. Atherosclerosis 1988;73:241-6.

4 Heim M, Bory M, Ardissone JP, De Rocca Serra M, Giordanella JP, Auquier P, et al. Les marqueurs lipidiques du risque vasculaire. Etude transversale d'un groupe d'hommes coronariens, d'un groupe à coronaires angiographiquement normales et d'un groupe témoin. angiographiquement normales et d'un gro

5 Figueroa O, Franco-Saenz R, Mulrow RJ, Montesinos E. Changes in cholesterol levels after coronary artery bypass surgery. $\mathrm{Am}$ f $\mathrm{Med}$ Sci 1992;303:73-7.

6 Trinder P. Determination of glucose in blood using glucose oxidase with an alternative oxygen acceptor. $A n n$ Clin Biochem 1969;6:24.

7 Kostner GM, Avogaro P, Bittolobon G, Cazzolatto G, Quinci GB. Determination of high density lipoprotein screening methods compared. Clin Chem 1979;25: 939-42.

8 Munscher G, Metzmanne E, Ziegenbein W. Standardization procedure of immunochemical apolipoprotein quantitation. Ric Clin Lab 1982;12:143-54.

9 Friedewald WT, Levy RI, Fredrikson DS. Estimation of the concentration of low density lipoprotein cholesterol in plasma without use of preparative ultracentrifugation. Clin Chem 1972;18:499-502.

10 Wilkinson L. Systat: the system for statistics. Evantson, IL: SYSTAT Inc, 1990

11 Woolson RF. Statistical methods for the analysis of biomedical data. New York: Wiley, 1987:337.

12 Genest J, McNamara J, Ordova JM, Jenner JL, Silberman SR, Anderson KM, et al. Lipoprotein cholesterol, apolipoprotein A I and B and lipoprotein (a) abnormalities in men with premature coronary artery disease. $₹ A m$ Coll Cardiol 1992;19:792-802.

13 Sigurdsson $G$ Baldursdottir A, Sigvaldason $H$, Agnarsson U, Thorgeirsson G, Sigfusson N. Predictive value of apolipoproteins in a prospective survey of coronary apolipoproteins in a prospective survey of coronary

14 Pomrehn P, Duncan B, Weissfeld L, Wallace RB, Barnes $R$, Heiss G, et al. The association of dyslipoproteinemia with symptoms and signs of peripheral arterial disease: the Lipid Research Clinics Program Prevalence Study Circulation 1986;73(suppl I):I-100-7

15 Romm PA, Green CE, Reagan K, Rackley CE. Relation of serum lipoprotein cholesterol levels to presence and severity of angiographic coronary artery disease. $\mathrm{Am} \mathfrak{f}$ Cardiol 1991;67:479-83.

16 Rifkind BM. High density lipoprotein cholesterol and coronary artery disease: survey of the evidence. $A m \mathcal{F}$ Cardiol 1990;66:3-6A

17 Gordon DJ, Probstfield JL, Garrison R, Neaton JD. High density lipoprotein cholesterol and cardiovascular disdensity lipoprotein cholesterol and cardiovascular disease: four prosp
1989;79:8-15.

18 Manninen V, Tenkanen L, Koskinen $\mathrm{P}$, Huttunen JK, Männtäri $M$, Heinonen $O$, et al. Joint effects of serum Männtäri $M$, Heinonen $O$, et al. Joint effects of serum
triglycerides and $\mathrm{LDL}$ cholesterol and $\mathrm{HDL}$ cholesterol

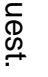


concentrations on coronary heart disease. Risk in the Helsinki study. Implications for treatment. Circulation 1992;85:37-45

19 Chivot L, Mainard F, Bigot E, Bard JM, Auget JL, Madec $\mathrm{Y}$, et al. Logistic discriminant analysis of lipids and apolipoproteins in a population of coronary bypass patients and the significance of apolipoproteins CIII and E. Atherosclerosis 1990;82:205-11.

20 Castelli WP. Epidemiology of coronary heart disease. $A m \mathcal{F}$ Med 1984;96:4-12.

21 Lehtonen A, Marniemi J, Inberg M, Maatela J, Alanen E, Niittyaki K. Levels of serum lipids, apolipoprotein A I and $B$ and pseudocholinesterase activity and their discriminative values in patients with coronary bypass operation. Atherosclerosis 1986;59:215-21.

22 Austin MA. Plasma triglycerides as a risk factor for coronary heart disease: the epidemiologic evidence and beyond. Am $\mathcal{F}$ Epidemiol 1989;129:249-59.

23 Ryu JE, Howard G, Craven TE, Bond MG, Hagaman AF Crouse JR. Post-prandial triglyceridemia and carotid atherosclerosis in middle-aged subjects. Strok 1992;23:823-8.

24 Tverdal A, Foss OP, Leren P, Holme I, Lund-Larson PG, Bjarveit K. Serum triglycerides as an independent risk Bjarveit $\mathrm{K}$. Serum triglycerides as an independent risk factor for death from coronary heart disease in middleaged Norwegian men. Am f Epidemiol 1989;129:458-65.

25 Trayner IM, Mannarino E, Clyne CAC, Thompson GR Serum lipids and high-density lipoproteins in peripheral vascular disease. Brf Surg 1980;67:497-9.
26 Brischetto CS, Connor WE, Connor SL, Matarazzo JD. Plasma lipid and lipoprotein profiles of cigarette smokers from randomly selected families: enhancement of hyperlipidemia and depression of high-density lipoprotein. $A m$ $\mathcal{f}$ Cardiol 1983;52:675-80.

27 Craig WY, Palomaki JE, Haddow J. Cigarette smoking and serum lipid and lipoprotein concentrations: analysis of published data. $B M F$ 1989;298:784-8.

28 Cuesta C, Sanchez-Muniz FJ. Effects of age and cigarette smoking on serum concentrations of lipids and apolipoproteins in a male military population. Atherosclerosis proteins in a

29 Criqui $\mathrm{MH}$, Cowan LD, Heiss G, Haskell WL Laskarzewski PM, Chambless LE. Frequency and clustering of non-lipid coronary risk factors in dyslipoproteinemia: the Lipid Research Clinics Progran Prevalence Study. Circulation 1986;73(suppl I):40-9.

30 Sönnichsen AC, Richter WO, Schwandt F. Body fat distribution and serum lipoproteins in relation to age and body weight. Clin Chim Acta 1991;202:133-40.

31 Howard B. Obesity, lipoproteins and heart disease. Proc Soc Exp Biol Med 1992;200:202-5.

32 Kannel WB, Shurtleff D. The Framingham study: cigarettes and the development of intermittent claudication. Geriatrics 1973;28:61-8.

33 Lagrue G, Marcel GA, Faucher G, Gallais M, Branellec A. Déformalité érythrocytaire: influence du tabagisme et
des facteurs de risque vasculaire. La Nouvelle Presse Médicale 1979;8:4079-81. 